\title{
Targeted eicosanoid lipidomics of exhaled breath condensate provide a distinct pattern in the aspirin-intolerant asthma phenotype
}

\author{
Marek Sanak, MD, Anna Gielicz, MSc, Grażyna Bochenek, MD, Marek Kaszuba, MD, Ewa Niżankowska-Mogilnicka, MD, \\ and Andrew Szczeklik, MD Krakow, Poland
}

Background: Eicosanoids, important signaling and inflammatory molecules, are present in exhaled breath condensate $(\mathrm{EBC})$ in very low concentrations, requiring highly sensitive analytic methods for their quantification. Objective: We sought to assess a vast platform of eicosanoids in different asthma phenotypes, including aspirin-intolerant asthma, by means of a recently developed analytic approach based on mass spectrometry.

Methods: EBC from 115 adult asthmatic subjects (62 with aspirin intolerance) and 38 healthy control subjects were assessed quantitatively for 19 eicosanoids by using complementary HPLC, gas chromatography-mass spectrometry, or both. Palmitic acid concentrations were used as a marker for dilution of condensate samples.

Results: Asthma was characterized by an increase in arachidonate lipoxygenase products and cysteinyl leukotrienes. The COX pathway was also significantly upregulated in asthmatic subjects. Subjects with aspirin-intolerant asthma were distinguished by a sharp increase in the level of prostaglandin $\mathrm{D}_{2}$ and $\mathrm{E}_{2}$ metabolites; their 5- and 15hydroxyeicosateraenoic acid levels were also higher than in aspirin-tolerant subjects. A classical discriminant analysis permitted us to classify correctly $99 \%$ of asthmatic subjects within the study population; the specificity of the analysis was 97\%. The eicosanoid profiling allowed for $92 \%$ correct classification of aspirin-intolerant subjects.

Conclusions: The highly sensitive eicosanoid profiling in EBC makes it possible to detect alterations in asthma, especially in its distinct phenotype characterized by hypersensitivity to aspirin and other nonsteroidal anti-inflammatory drugs. This permits us to discriminate asthmatic subjects from healthy subjects, as well as to distinguish the 2 asthma phenotypes based on the presence or absence of aspirin hypersensitivity. ( $\mathrm{J}$ Allergy Clin Immunol 2011;127:1141-7.)

\footnotetext{
From the Department of Medicine, Jagiellonian University Medical College.

Supported by a grant from Iceland, Liechtenstein, and Norway through the European Economic Area (EEA) Financial Mechanism and by the U-BIOPRED project carried out under the Innovative Medicines Initiative.

Disclosure of potential conflict of interest: M. Sanak, A. Gielicz, G. Bochenek, M Kaszuba, E. Nizankowska-Mogilnicka, and A. Szczeklik have received research support from the European Community and the Polish Ministry of Science and Higher Education.

Received for publication October 22, 2010; revised December 22, 2010; accepted for publication December 30, 2010.

Available online February 11, 2011

Reprint requests: Andrew Szczeklik, MD, Department of Medicine, Jagiellonian University Medical College, Ul. Skawinska 8, 31-066 Krakow, Poland. E-mail: mmszczek@ cyf-kr.edu.pl.

$0091-6749 / \$ 36.00$

(C) 2011 American Academy of Allergy, Asthma \& Immunology

doi:10.1016/j.jaci.2010.12.1108
}

Key words: Exhaled breath condensate, asthma, aspirin intolerance, eicosanoids, mass spectrometry

The breath, like the heartbeat, has always been a mark of life, an expression of its mystery. Breath composition has recently started to be analyzed in airway physiology and pathology. ${ }^{1}$ This approach appeals to researchers and clinicians. It provides them with a sample of air from the respiratory tract obtained through a noninvasive procedure, which can be repeated several times. The exhaled air contains both volatile and nonvolatile compounds, which might include potential biomarkers. Volatile organic compounds, derived from various metabolic pathways in the lung and elsewhere in the body, can be detected by using an integrative array of microsensors ("electronic nose"). This method might yield distinctive patterns for asthma and chronic obstructive pulmonary disease. ${ }^{2}$ However, it cannot identify individual volatile organic compounds. This requires mass spectrometry, ${ }^{3}$ which also is a gold standard for detecting nonvolatile compounds. The latter are present in such a low concentration that methods other than tandem mass spectrometry barely reach the threshold of their detection.

Nonvolatile compounds are usually studied in exhaled breath condensate (EBC). ${ }^{4}$ During tidal breathing, lasting 15 to 20 minutes, the air is directed through a 1-way expiratory valve to a cooling trap, resulting in the accumulation of 1 to $2 \mathrm{~mL}$ of clear liquid. The vast majority of this liquid is composed of water, but a tiny fraction contains nonvolatile compounds. It is assumed that they are present in the liquid that lines the airway and that they become aerosolized during inflation of the lung and carried up with exhaled airflow.

Of various mediators active in asthma, the derivatives of arachidonic acid, eicosanoids, occupy a special place. Marked alterations in their biosynthesis have been demonstrated in a clear-cut phenotype of asthma (ie, aspirin-induced asthma [AIA $])^{5,6}$ and suggested in other asthma phenotypes. ${ }^{7}$ We hypothesized that EBC analysis might provide new insight into the alteration of these eicosanoids. Therefore we applied our own analytic approach based on mass spectrometry. ${ }^{8}$ This recently developed approach has allowed us to assess a vast platform of eicosanoids in different asthma phenotypes.

\section{METHODS}

\section{Subjects studied}

The patients were recruited from the outpatient clinic of our department All were in stable condition, with no signs of recent respiratory tract infection. No changes in current therapy were requested, except withholding of shortacting $\beta$-mimetics for 4 hours preceding the EBC collection.

In patients with AIA, the disease developed according to a pattern characterized by a sequence of symptoms. ${ }^{9}$ They had at least 1 asthma attack after an ingestion of aspirin or another nonsteroidal anti-inflammatory drug in the past, and this diagnosis was confirmed by means of either oral or bronchial 
Abbreviations used

AIA: Aspirin-intolerant asthma

ATA: Aspirin-tolerant asthma

EBC: Exhaled breath condensate

8-iso-PGF ${ }_{2 \alpha}$ : Isoprostane $\mathrm{F}_{2 \alpha}$

11-dehydro- $\mathrm{TXB}_{2}$ : Thromboxane $\mathrm{A}_{2}$ metabolite

GC-MS: Gas chromatography-mass spectrometry

HPLC-MS/MS: High-performance liquid chromatographytandem mass spectrometry

HETE: Hydroxyeicosatetraenoic acid

LO: Lipoxygenase

LT: Leukotriene

$9 \alpha, 11 \beta-\mathrm{PGF}_{2}: \mathrm{PGD}_{2}$ semistable metabolite

PG: Prostaglandin

PGEM: $\mathrm{PGE}_{2}$ stable metabolite

6-keto-PGF ${ }_{1 \alpha}$ : Prostacyclin metabolite

provocation tests with aspirin performed within 1 year before the study. In oral challenge tests $(n=46)$ mean $\mathrm{PD}_{20}$ was $98.3 \mathrm{mg}(20-187 \mathrm{mg})$ of acetylsalicylic acid, and in inhalation tests $(\mathrm{n}=16)$ it was $6.4 \mathrm{mg}(0.3-26.0 \mathrm{mg})$ of acetylsalicylic acid. Sixteen patients (10 with aspirin-tolerant asthma [ATA] and 6 with AIA) were receiving leukotriene (LT) receptor antagonists. No patient received an inhibitor of LT biosynthesis or aspirin desensitization treatment.

Asthmatic subjects who tolerated aspirin well within the previous 2 years had occasionally used aspirin and denied any adverse effects when specifically queried. In 16 subjects with ATA selected at random, an aspirin challenge test was performed; results were negative in all cases.

The assessment of asthma severity was based on the National Asthma Education and Prevention Program's Expert Panel Report $3 .{ }^{10}$ The current symptoms of asthma, bronchodilator use, limitation of normal activity, current lung function, and frequency of exacerbations in the last year were taken into account. Asthma severity was classified as intermittent, mild persistent, moderate persistent, and severe persistent. Each subject was assigned to the highest level at which any feature occurred.

Asthma control was assessed by using the Asthma Control Test. ${ }^{11}$ It consisted of 5 items rated on a 1- to 5-point scale, which reflected the level of asthma control in the previous 4 weeks. The maximum score possible was 25 . The subject was categorized as having well-controlled asthma if his or her score equaled 25. A score of 20 to 24 categorized the subject as having partly controlled asthma, and a score of less than 20 categorized the subject as having poorly controlled disease.

The control group (Table I) consisted of healthy subjects with no history of asthma or allergy who were recruited from the university hospital staff. All subjects provided informed consent to participate in the study, and the protocol was approved by the university's ethics committee.

\section{EBC collection and sample preparation}

Collections of EBC were carried out with the ECO Screen I (Jaeger GmbH, Hoechberg, Germany) equipped with a saliva trap, according to American Thoracic Society/European Respiratory Society recommendations. ${ }^{4}$ After tidal breathing for 15 minutes, $2 \mathrm{~mL}$ of clear fluid was collected and immediately transferred on ice to $\mathrm{a}-70^{\circ} \mathrm{C}$ freezer. Samples were stored frozen until extraction, which was completed within 3 months. After thawing on ice, the $\mathrm{pH}$ of the condensate was adjusted to 3.5 by using acetic acid $(2 \mu \mathrm{L})$ and added methanol solution of internal deuterated standards containing 5-hydroxyeicosatetraenoic acid (HETE)- $\mathrm{d}_{8}, 12-$ HETE-d $\mathrm{d}_{8}, 15-$ HETE- $\mathrm{d}_{8}$, LTD $_{4}-\mathrm{d}_{5}$, LTE $_{4}-\mathrm{d}_{3}$, LTB $_{4}-\mathrm{d}_{4}(0.5$ ng each), tetranor-PGE ${ }_{2}$ stable metabolite (PGEM) $-\mathrm{d}_{6}(5 \mathrm{ng})$, prostaglandin (PG) $\mathrm{E}_{2}-\mathrm{d}_{4}, \mathrm{PGD}_{2}-\mathrm{d}_{4}, \mathrm{PGD}_{2}$ semistable metabolite $\left(9 \alpha, 11 \beta-\mathrm{PGF}_{2}\right)-\mathrm{d}_{4}(0.25$ ng each), prostacyclin metabolite (6-keto- $\left.\mathrm{PGF}_{1 \alpha}\right)-\mathrm{d}_{4}$, isoprostane $\mathrm{F}_{2 \alpha}$ (8-iso$\left.\mathrm{PGF}_{2 \alpha}\right)-\mathrm{d}_{4}$, thromboxane $\mathrm{A}_{2}$ metabolite (11-dehydro- $\left.\mathrm{TXB}_{2}\right)-\mathrm{d}_{4}(0.5 \mathrm{ng}$ each, all from Cayman Chemical Co, Ann Arbor, Mich), and palmitic acid-d ${ }_{4}$ (40 ng; Dr Ehrenstorfer GmbH, Augsburg, Germany). The sample was extracted twice with $1 \mathrm{~mL}$ of tert-butyl methyl ether. Organic phases were combined and evaporated under nitrogen at room temperature. Residue was dissolved in methanol $(60 \mu \mathrm{L})$ and immediately used for further analyses.

\section{HPLC-tandem mass spectrometry}

The EBC extract ( $10 \mu \mathrm{L}$ in methanol) was injected onto a reverse phase column (Zorbax Eclipse XDB C-18; Agilent Technologies, Inc, Santa Clara, Calif) stabilized thermally at $37^{\circ} \mathrm{C}$. HPLC with an autosampler (Shimadzu Sil2-AC; Shimadzu Scientific Instruments, Inc, Columbia, Md) was coupled to a tandem mass spectrometer (Qtrap 4000; Applied Biosystems, Foster City, Calif) equipped with an electrospray ion source. Analytes were measured by using the multiple-reaction monitoring mode. Chromatographic solvents, binary gradient and flow conditions, ionization modes, retention times, and diagnostic ions were as previously described. ${ }^{8}$

\section{Gas chromatography-mass spectrometry}

EBC extracts were prepared by means of a 3-step derivatization to pentafluorobenzyl ester, trimethylsilyl esters, and methoxyoxime, which modified the carboxyl, hydroxyl, and keto groups of eicosanoids. After purification with thin-layer chromatography, gas chromatography negativeion chemical ionization mass spectrometry (model Engine 5989B series II; Hewlett-Packard, Palo Alto, Calif; for details see Sanak et al ${ }^{8}$ ) was used to measure prostanoids that could not be separated with HPLC-tandem mass spectrometry (HPLC-MS/MS; $9 \alpha, 11 \beta-\mathrm{PGF}_{2}, \mathrm{PGF}_{2 \alpha}$, and 8 -iso- $\mathrm{PGF}_{2}$ ) and palmitic acid.

$\mathrm{PGE}_{2}, \mathrm{PGD}_{2}, \mathrm{PGI}_{2}$ metabolite, and thromboxane $\mathrm{A}_{2}$ (11-dehydro-TXB ${ }_{2}$ ) values were ascertained by using both methods. A discrepancy observed previously between $\mathrm{PGE}_{2}$ measurements by means of HPLC-MS/MS and gas chromatography-mass spectrometry $(\mathrm{GC}-\mathrm{MS})^{8}$ was resolved ultimately. GC-MS measurements of $\mathrm{PGE}_{2}$ overestimated its concentration because it was overlayed with isoprostane 8 -iso- $\mathrm{PGE}_{2}$. A corrected GC-MS analysis, ${ }^{12}$ which discriminated between the 2 compounds, resulted in a highly significant correlation of $\mathrm{PGE}_{2}$ measured by using the 2 methods $(R=0.908)$. For other double-measured eicosanoids, correlation coefficients were as follows: $R\left[6-\right.$ keto-PGF ${ }_{1 \alpha}$ ], 0.982; $R$ [11-dehydro- $\mathrm{TXB}_{2}$ ], 0.959; and $R\left[\mathrm{PGD}_{2}\right.$ ], 0.243. The latter, similar to uncorrected GC-MS measurements of $\mathrm{PGE}_{2}$, were overestimated by using this method. A possible interference between $\mathrm{PGD}_{2}$ and isoprostane $\mathrm{D}_{2}$ or other structurally related compounds could not be resolved in the current study because no appropriate standard compounds were available. It is noteworthy that the GC-MS bias of $\mathrm{PGD}_{2}$ measurements was highest in the asthmatic subjects, whereas in healthy control subjects the measurements correlated with the HPLC-MS/MS method satisfactorily $(R=0.529)$. Further analysis was restricted to HPLC-MS/MS data, except the eicosanoids were measured only with GC-MS. All solvents were of HPLC grade (Mallincrodt Baker, Inc, Phillipsburg, NJ), and other chemicals were from SigmaAldrich Co (St Louis, Mo).

Concentrations of the measured analytes were calculated by using a stable isotope dilution method. Data are presented as medians with interquartile ranges (25th and 75th percentiles). Both raw data and relative concentrations corrected for EBC dilution with palmitic acid are reported. The rationale for the method of correction for variable EBC dilution factor with palmitic acid has been described previously. ${ }^{8}$

Between-group comparisons were done with a nonparametric MannWhitney test. Asthmatic subjects were contrasted with healthy control subjects. Comparisons between subjects with AIA and asthmatic subjects who tolerated aspirin well (ATA) were done with the same method. The statistical significance of differences was verified with the Conover-Inman method for pairwise comparisons. A discriminant analysis was performed on the data corrected for dilution factor by using relative concentrations. For all measured compounds, a quadratic model was used because of a high crosscorrelation between eicosanoid concentrations. An alternate forward stepwise discriminant analysis was done with a linear model. The model entry criterion was arbitrarily defined as an increase $F$ statistics by more than 1 . Prior probabilities for the discriminant analysis were calculated from the group sizes. All calculations were done with SPSS for Windows version 17.0 (SPSS, Inc, Chicago, Ill). 
TABLE I. Clinical characteristics of the study subjects

\begin{tabular}{|c|c|c|c|c|}
\hline & $\begin{array}{l}\text { Asthmatic subjects } \\
\qquad(n=115)\end{array}$ & $\begin{array}{l}\text { Subjects with } \\
\text { aspirin-intolerant } \\
\text { asthma }(n=62)\end{array}$ & $\begin{array}{l}\text { Subjects with ATA } \\
(\mathrm{n}=53)\end{array}$ & $\begin{array}{l}\text { Healthy control } \\
\text { subjects }(n=38)\end{array}$ \\
\hline Male/female subjects & $41 / 74$ & $21 / 41$ & $20 / 33$ & $12 / 26$ \\
\hline Current smokers & 3 & 3 & 0 & 10 \\
\hline Duration of asthma & $18.61 \pm 11.8$ & $19.84 \pm 9.2 \dagger$ & $17.11 \pm 14.3$ & NA \\
\hline Atopy, no. (\%) & $56(48.7)$ & $28(45.2)$ & $28(52.8)$ & NA \\
\hline $\begin{array}{l}\text { Total serum IgE }(\mathrm{IU} / \mathrm{mL}) \\
\text { median }(25 \text { th- } 75 \text { th percentile) }\end{array}$ & $101(41.6-220)$ & $100.2(44.7-180.0)$ & $116(24-268.5)$ & NA \\
\hline $\operatorname{FEV}_{1}(\%)$ & $80.56 \pm 18.4$ & $77.10 \pm 18.6 \dagger$ & $84.87 \pm 17.5$ & NA \\
\hline Asthma severity (NAEPP-EPR3) & $2.43 \pm 1.1$ & $2.86 \pm 1.0 \S$ & $1.90 \pm 1.1$ & NA \\
\hline
\end{tabular}

$A C T$, Asthma Control Test; NA, not applicable; NAEPP-EPR, National Asthma Education and Prevention Program's Expert Panel Report 3.

$* P<.001$ for the contrast between asthmatic and healthy control subjects.

$\dagger P<.05, \ddagger P<0.01$, or $\S P<.001$ for the contrast between subjects with aspirin-intolerant asthma and subjects with ATA.

\section{RESULTS}

\section{Characteristics of asthmatic subjects}

One hundred fifteen asthmatic subjects were recruited, 62 (41 female subjects) of whom had AIA. Asthmatic subjects who tolerated aspirin well (ie, those with ATA; $\mathrm{n}=53 ; 33$ female subjects) were younger, on average, by 5 years $(P<.01)$ than subjects with AIA. The duration of asthma was longer by 2.7 years in subjects with AIA $(P<.05)$. Atopy status, defined as a documented positive skin prick test reaction for common allergens, the presence of allergen-specific IgE at a concentration exceeding $35 \mathrm{IU} / \mathrm{mL}$, or both, did not differ between the groups. Peripheral blood eosinophil counts tended to be higher in subjects with AIA $(P=.08)$, whereas total serum IgE levels were not different. Subjects with ATA had lower forced expiratory flow $(P<.05)$ and asthma severity scores $(P<.001)$. Roughly $50 \%$ of asthmatic subjects had at least partly controlled and the rest poorly controlled disease, without any differences $(P=.43)$ between the groups. The groups did not differ in terms of dosage of topical or systemic corticosteroids. The characteristics of the study subjects are summarized in Table I.

\section{Palmitic acid and eicosanoids in EBC: Correlation with pulmonary function in asthmatic subjects}

Palmitic acid did not show any correlation $(R=0.151)$ with $\mathrm{FEV}_{1}$ in the entire asthmatic group. However, subjects with ATA analyzed alone demonstrated a significant negative correlation between the concentration of palmitic acid and $\operatorname{FEV}_{1}(R=$ $-0.384, P=.005)$, whereas such a correlation was absent in the AIA group $(R=0.019)$. Of other eicosanoids quantified, 6keto-PGF ${ }_{1 \alpha}$ correlated positively and significantly $(R=0.378$, $P=.003)$ with $\mathrm{FEV}_{1}$ in subjects with ATA $(R=0.024)$ but not in the AIA group. In the AIA group the only significant predictor of decreased $\mathrm{FEV}_{1}$ was increased $9 \alpha, 11 \beta-\mathrm{PGF}_{2}$, the metabolite of $\mathrm{PGD}_{2}(R=-0.374, P=.015)$, which did not correlate with $\mathrm{FEV}_{1}$ in subjects with ATA $(R=0.121)$.

\section{Sex differences}

Nonparametric comparison of EBC eicosanoids and palmitic acid between men and women did not reveal any significant differences. Within the whole asthmatic group, $\mathrm{LTD}_{4}$ levels tended to be higher in men ( 2.2 vs $1.9 \mathrm{ppm}, P=.048)$, and PGEM levels were higher in women ( 323 vs $138 \mathrm{ppm}, P=$ .023). Further stratification of asthmatic subjects into aspirinintolerant and aspirin-tolerant phenotypes showed higher eoxin $\mathrm{D}_{4}$ levels in female subjects in cases of aspirin tolerance (2.4 vs $1.4 \mathrm{ppm}, P=.032$ ).

\section{Eicosanoid EBC concentrations in asthmatic versus healthy control subjects}

Subjects with asthma had levels of all 3 lipoxygenase (LO) products increased. A significant increase in 5-HETE, 12-HETE, and 15-HETE levels was accompanied by an increase in $\mathrm{LTC}_{4}$, $\mathrm{LTD}_{4}$, and $\mathrm{LTE}_{4}$, but not $\mathrm{LTB}_{4}$, levels. Eoxins $\mathrm{C}_{4}, \mathrm{D}_{4}$, and $\mathrm{E}_{4}$ and lipoxin $\mathrm{A}_{4}$ levels did not differ from those in the control group. Metabolites of $\mathrm{PGD}_{2}, \mathrm{PGE}_{2}$, and prostacyclin $\left(\mathrm{PGI}_{2}\right)$, as well as $\mathrm{PGF}_{2 \alpha}, 8$-iso- $\mathrm{PGF}_{2}$, and 11-dehydro- $\mathrm{TXB}_{2}$, were all increased in asthmatic subjects. The results were similar when expressed as dilution-unadjusted concentrations, although statistical significance was less frequently encountered (Table II and see Table E1 in this article's Online Repository at www.jacionline.org).

\section{Differences between subjects with aspirin- intolerant asthma and those with ATA}

The most striking difference between aspirin-intolerant asthma and ATA was a vast increase of metabolites of $\mathrm{PGE}_{2}$ and $\mathrm{PGD}_{2}$ in the former group. In subjects with $\mathrm{AIA}, \mathrm{PGE}_{2}$ showed a tendency toward decreased values, which did not reach statistical significance. These patients had also increased levels of 5-HETE and 15-HETE. Cysteinyl LT and eoxin levels, however, were lower in subjects with AIA. Results obtained by means of evaluation 
TABLE II. Eicosanoid concentration in EBC as parts per million of palmitic acid

\begin{tabular}{|c|c|c|c|c|}
\hline & $\begin{array}{l}\text { Asthmatic subjects } \\
\qquad(\mathrm{n}=116)\end{array}$ & $\begin{array}{l}\text { Subjects with } \\
\text { aspirin-intolerant } \\
\text { asthma }(n=62)\end{array}$ & $\begin{array}{l}\text { Subjects with ATA } \\
(n=54)\end{array}$ & $\begin{array}{l}\text { Healthy control } \\
\text { subjects }(n=38)\end{array}$ \\
\hline 5-HETE & $7.51(4.18-13.48)$ & $8.92(4.26-17.56) \S$ & $6.23(4.15-9.49)$ & $4.29(3.15-7.55) \dagger$ \\
\hline 15-HETE & $10.53(5.74-22.72)$ & $15.09(5.85-28.46) \S$ & $8.79(4.40-14.96)$ & $5.19(2.87-7.44) \ddagger$ \\
\hline $\mathrm{PGE}_{2}$ & $1.74(0.79-3.06)$ & $1.13(0.49-3.11)$ & $1.82(1.12-2.83)$ & $1.64(0.90-3.10)$ \\
\hline PGEM & $292(128-450)$ & $387(222-515) 9$ & $144(77.4-293)$ & $76.1(36.5-220) \ddagger$ \\
\hline $\mathrm{LTB}_{4}$ & $12.92(7.15-19.38)$ & $16.18(7.68-23.04)$ & $10.02(7.00-16.11)$ & $16.19(11.08-25.20)^{*}$ \\
\hline $\mathrm{LTC}_{4}$ & $4.28(2.68-8.13)$ & $3.69(2.39-7.03)$ & $5.59(3.01-9.56)$ & $2.28(0.81-5.43) \dagger$ \\
\hline $\mathrm{LTD}_{4}$ & $2.69(1.32-5.42)$ & $1.93(0.96-4.09) \|$ & $3.77(2.09-6.94)$ & $1.80(0.80-4.09)^{*}$ \\
\hline $\mathrm{LTE}_{4}$ & $3.40(1.99-5.49)$ & $2.54(1.37-4.66) \Phi$ & $4.52(2.96-6.87)$ & $2.03(1.39-4.05)^{*}$ \\
\hline Eoxin $\mathrm{C}_{4}$ & $1.07(0.60-1.99)$ & $0.77(0.34-1.52)$ व & $1.42(0.80-2.81)$ & $1.06(0.65-1.92)$ \\
\hline Eoxin $\mathrm{D}_{4}$ & $1.30(0.65-2.60)$ & $0.70(0.40-1.30)$ ฯ & $2.02(1.21-3.08)$ & $1.47(1.95-3.73)$ \\
\hline 8-Iso-PGF 2 & $0.77(0.45-1.26)$ & $0.79(0.36-1.52)$ & $0.76(0.54-1.08)$ & $0.46(0.34-0.87)^{*}$ \\
\hline Lipoxin $\mathrm{A}_{4}$ & $0.69(0.40-1.11)$ & $0.63(0.39-1.09)$ & $0.85(0.48-1.17)$ & $0.94(0.44-1.90)$ \\
\hline
\end{tabular}

Values are presented as medians (25th-75th percentiles).

$* P<.05, \dagger P<.01$, or $\ddagger P<.001$ for the contrast between asthmatic and healthy control subjects.

$\S P<.05, \| P<.01$, or $\uparrow P<.001$ for the contrast between subjects with aspirin-intolerant asthma and subjects with ATA.

of dilution-unadjusted concentrations were very similar (Table II and see Table E1).

\section{Effect of glucocorticosteroid therapy on palmitic acid and eicosanoids in EBC}

The palmitic acid concentration in EBC was significantly lower in asthmatic subjects treated with glucocorticosteroids $(459 \pm 197$ vs $543 \pm 257 \mathrm{ng} / \mathrm{mL}, P=.03)$. This difference, however, disappeared when $\mathrm{FEV}_{1}$ was entered as a covariate into ANOVA $(P=.4)$. Asthmatic subjects receiving glucocorticosteroids (oral corticosteroid treatment and/or inhaled corticosteroid dose exceeding $250 \mu \mathrm{g}$ of fluticasone equivalent daily) had noticeably lower 8 -isoPGF ${ }_{2 \alpha}$ levels than untreated subjects $(\mathrm{n}=91,1.0 \mathrm{vs}$ $1.64 \mathrm{ppm}, P=.034)$. Only subjects with AIA had higher eoxin $\mathrm{E}_{4}$ levels if treated with glucocorticosteroids ( $\mathrm{n}=45,5.5$ vs 1.9 ppm, $P=.03$ ). Neither of the measured eicosanoids correlated with glucocorticosteroid treatment in the whole group of asthmatic subjects or in asthmatic subjects stratified by tolerance to aspirin.

\section{Discriminant analysis of eicosanoids as predictors of asthmatic phenotype}

By using a classical stepwise binary discriminant analysis, in which the presence of asthma was predicted on adjusted concentrations of all measured eicosanoids, only 4 markers fulfilled the criteria of probabilities to enter to the model. Canonical discriminant function, which predicted the presence of asthma, had the following standardized coefficients: 5-HETE, 0.41; $\mathrm{LTD}_{4}, 0.30$; $\mathrm{PGE}_{2},-0.72$; and 6-keto-PGF ${ }_{1 \alpha}, 1.01$. The mean function value for control subjects was significantly lower than for asthmatic subjects $(-1.11$ vs $0.32, P<.001)$. By using this function, $95 \%$ of asthmatic subjects were correctly stratified, but $53 \%$ of control subjects were misclassified as having asthma.
Classification of the study subjects into healthy control or asthma groups, irrespective of their tolerance to aspirin, was almost perfect by using all the measurements of eicosanoids (total of $99 \%$ correctly classified). Misclassification was encountered in the control group, in which $3 \%$ of subjects were categorized as being asthmatics.

A similar but ternary model built on a stepwise entry of eicosanoid measurements had slightly limited specificity for classification of the study subjects into 3 groups: subjects with AIA, subjects with ATA, and healthy control subjects. It required 12 of 19 measured analytes. Misclassification affected subjects with ATA (total of 7\%, 2\% categorized as aspirin intolerant and $5 \%$ as healthy control subjects; Fig 1). By using this limited set of measurements, the worst specificity was in healthy control subjects (total of $73 \%$ correctly categorized, $5 \%$ misclassified as having AIA and $19 \%$ as having ATA). Nevertheless, overall performance showed a $92 \%$ correct diagnosis. The ternary model of a discriminant analysis using all the measurements correctly categorized $99 \%$ of the study subjects (Fig 2). The only misclassification was 1 subject with AIA categorized in the ATA group. The eicosanoids entered into discrimination function are listed in Table E2 (available in this article's Online Repository at www.jacionline.org) for both ternary models. In these models of discriminant analysis, healthy control subjects were characterized by a lower value of canonical factor 2 than seen in asthmatic subjects. The phenotype of AIA versus ATA was discriminated by a difference in the load of canonical factor 1, being smaller for subjects with ATA in the all measurements model.

\section{DISCUSSION}

In the present study we used a validated analytic platform ${ }^{13,14}$ to analyze eicosanoids in EBC of asthmatic subjects. The study subjects were contrasted for the triggering phenotype (ie, AIA [aspirin- 


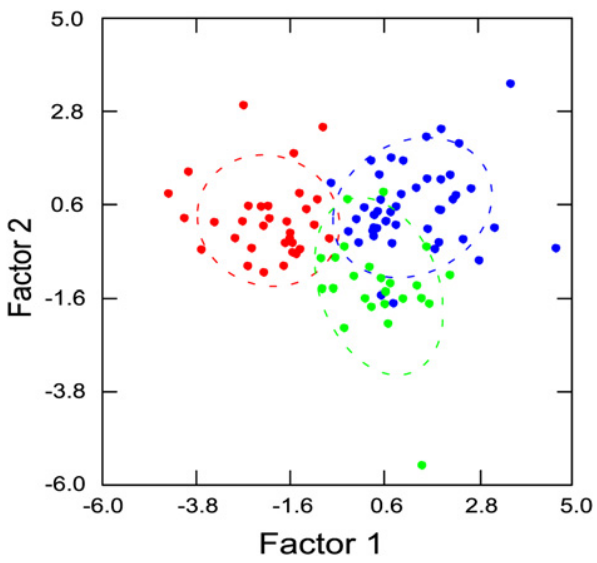

FIG 1. Discriminant analysis based on stepwise selection of 12 eicosanoids in EBC. The overall performance of the ternary model built on a stepwise entry of eicosanoid measurements was a $92 \%$ correct diagnosis. Color codes for subjects are as follows: red, subjects with aspirin-intolerant asthma; blue, subjects with ATA; and green, healthy control subjects.

exacerbated respiratory disease] vs ATA). Patterns of eicosanoid mediators in subjects with AIA have previously been reported in several biological matrices: blood plasma, ${ }^{15}$ bronchoalveolar lavage fluid, ${ }^{16}$ nasal lavage fluid, ${ }^{17,18}$ sputum, ${ }^{19,20}$ and urine ${ }^{21,22}$ and, to a much lesser extent, EBC. ${ }^{23,24}$ After the oral aspirin challenge test, the starkest differences in eicosanoid production were found in urine, ${ }^{21,22}$ reflecting increased systemic biosynthesis of cysteinyl LTs, the main eicosanoid culprit for asthmatic attack. In aspirin-intolerant subjects, even those in stable clinical condition, increased $\mathrm{LTE}_{4}$ urinary excretion is a hallmark of the disease.

The aim of this study was to compare patterns of eicosanoids released to the epithelial surface of the asthmatic lung in subjects with well-defined aspirin hypersensitivity. Because of the lack of an in vitro test to diagnose aspirin hypersensitivity, the rationale of our study was to investigate the discriminant properties of EBC eicosanoids. To determine the patterns of eicosanoids produced within the lung during an asthmatic inflammation, we introduced some novel concepts for the standardization of EBC material measurements. A highly sensitive method of mass spectrometry was used; it still requires some improvements to avoid a bias caused by the similarity between PGs and isoprostanes. ${ }^{14}$ The concurrent measurement of palmitic acid content in EBC seems a convenient surrogate for compensating the dilution factor, ${ }^{8}$ although alternative methods are available. ${ }^{25}$ A dilution of nonvolatile compounds with water has recently been demonstrated to vary between the subjects by more than 1 order of magnitude and to depend on ventilation mechanics. ${ }^{26,27}$ It is of interest that in our data forced expiratory flow was higher in subjects with increased levels of 6-keto-PGF ${ }_{1 \alpha}$ metabolite, possibly because prostacyclin in some, ${ }^{28}$ but not all, ${ }^{29}$ phenotypes of asthma was demonstrated to exert a protective effect. This effect was absent in subjects with AIA, a phenotype in which prostacyclin was proved to have no bronchoprotective effect. ${ }^{30} \mathrm{~A}$ different mechanism of bronchial obstruction ${ }^{31}$ might operate in subjects with AIA, in whom enhanced biosynthesis of $\mathrm{PGD}_{2}$ correlated with the trapping of epithelial line fluid aerosol. Comparing 2 phenotypes of asthma defined by hypersensitivity for a triggering factor (ie, aspirin), we demonstrated a distinct inflammatory endophenotype in EBC of subjects with AIA.

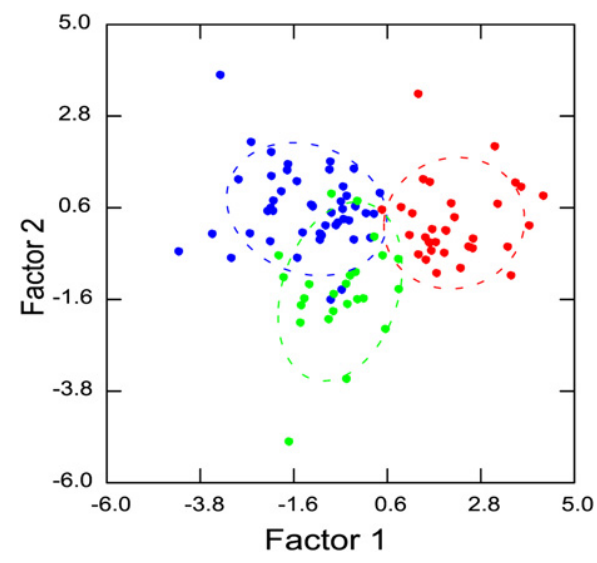

FIG 2. Discriminant analysis using all the measurements of eicosanoids in EBC. The ternary model of a discriminant analysis using all the measurements correctly categorized $99 \%$ of the study subjects. Color codes for subjects are as follows: red, subjects with aspirin-intolerant asthma; blue, subjects with ATA; and green, healthy control subjects.

Asthmatic inflammation was characterized by a significant increase in major arachidonate lipoxygenation products (ie, 5-HETE, 12-HETE, and 15-HETE). These findings corroborate with well-studied overexpression of LOs in the asthmatic lung. 5-LO and 15-LO are expressed not only in eosinophils and activated macrophages ${ }^{32}$ but also in lymphocytes and mast cells. ${ }^{33,34}$ The cellular origin of 12-LO is less clear; blood platelets are regarded as its main source. However, 12-LO was originally cloned from respiratory epithelia, where 15 -LO activity was also found.$^{35}$ In our study an increased concentration of arachidonate lipoxygenation products in the whole asthma group was accompanied by an increase in more active downstream mediators: the cysteinyl LTs $\mathrm{LTC}_{4}$, $\mathrm{LTD}_{4}$, and $\mathrm{LTE}_{4}$. As noticed previously, ${ }^{24}$ cysteinyl LT levels were not increased in EBC of subjects with AIA despite enhanced capacity for their biosynthesis, possibly because a vast majority of our patients were not steroid naive $\mathrm{e}^{23}$ but received a chronic steroid therapy. Glucocorticosteroid therapy affects only limited cell types in vivo, with major inhibiting effects limited to alveolar macrophages. ${ }^{36}$ In contrast to childhood asthma, ${ }^{37} 15$-LO analogues of cysteinyl LTs (ie, eoxins $\mathrm{C}_{4}, \mathrm{D}_{4}$, and $\mathrm{E}_{4}$ ) showed no increase. This might be perhaps due to a less frequent IgE-dependent mechanism operating in adults with asthma. However, atopy status did not correlate with eoxin levels in our data (data not shown).

The COX pathway was significantly upregulated in asthmatic subjects, as manifested by an excess of the most abundant prostanoid metabolites (ie, $\mathrm{PGI}_{2}$ and thromboxane $\mathrm{A}_{2}$ ). Levels of $\mathrm{PGF}_{2 \alpha}$ and its nonenzymatic isomer, 8-iso- $\mathrm{PGF}_{2}$, were also increased. In subjects with $\mathrm{AIA}, \mathrm{PGE}_{2}$ showed a tendency toward decreased values, which failed to reach significance; $\mathrm{PGD}_{2}$ values were unaltered. Anomalies in the synthesis of $\mathrm{PGE}_{2}$ along with the expression of its receptor, $\mathrm{PGE}_{2}$ receptor isoform 2 , have been associated with aspirin sensitivity (for reference see, Szczeklik et $\mathrm{al}^{38}$ ). Decreased $\mathrm{PGE}_{2}$ production was reported in epithelial cells of nasal polyps, peripheral blood cells, and bronchial fibroblasts compared with that seen in subjects with ATA, healthy subjects, or both. In a large genomic study ${ }^{39} \mathrm{PGE}_{2}$ receptor isoform 2 gene polymorphisms located in the regulatory region have been associated with aspirin hypersensitivity in asthmatic patients. We now demonstrate an excessive concentration of the $\mathrm{PGE}_{2}$ end metabolite PGEM in the lung of subjects with AIA, 
suggesting an enhanced turnover of $\mathrm{PGE}_{2}$. Upregulation of the $\mathrm{PGE}_{2}$ catabolic pathway could explain previously reported decreases in $\mathrm{PGE}_{2}$ levels in subjects with AIA but had to be accompanied by at least normal capacity for its synthesis. Indeed, at the systemic level, subjects with AIA had increased PGEM urinary excretion after aspirin challenge. ${ }^{22}$ More information derived from the mass spectrometric assays on other $\mathrm{PGE}_{2}$ metabolites, including $\mathrm{EBC}$ levels of the dinor- $\mathrm{PGE}_{2}$ intermediate, might shed more light on the site and nature of the anomalous $\mathrm{PGE}_{2} \mathrm{ki}$ netics in subjects with AIA. In contrast to the constant finding of increased urinary $\mathrm{LTE}_{4}$ levels in subjects with $\mathrm{AIA},{ }^{40}$ the subjects with controlled disease did not have increased cysteinyl LTs in EBC. The content of eicosanoids in the epithelial lining fluid is affected not only by biosynthesis but also by a polarized transepithelial release of prostanoids, ${ }^{41}$ and thus a possible interpretation of this phenomenon would suggest an inflammatory mechanism distinct from the asthmatic paradigm but more similar to a persistent viral infection. The current results are in line with our previous observation ${ }^{21}$ of increased urinary excretion of $\mathrm{PGE}_{2}$ stable metabolites in subjects with aspirin-intolerant asthma after aspirin challenge. In subjects with AIA, we also detected an increase in levels of the stable $\mathrm{PGD}_{2}$ metabolite, namely $9 \alpha, 11 \beta \mathrm{PGF}_{2}$. The increased values of this metabolite have been reported in the blood of subjects with AIA. ${ }^{15}$ In addition, after aspirin challenge, the blood and urinary levels of this metabolite increase. ${ }^{15}$ Mast cells are likely the source of this overproduction.

In summary, the highly sensitive eicosanoid profiling in EBC points to alterations in asthma, especially in its distinct phenotype characterized by aspirin and other nonsteroidal anti-inflammatory drug hypersensitivity. In our opinion the assessment of EBC does not yet seem to be practically applicable in routine clinical workup because of the limited availability of expensive equipment. Instead, the monitoring of anti-inflammatory intervention, as well as the progress of asthma, seems to fit this noninvasive procedure best.

We thank Joanna Kuschill-Dziurda, MD, for collection of clinical data on subjects with aspirin-intolerant asthma, and Krzysztof Nagraba, PhD, for technical expertise in GC-MS measurements.

Clinical implications: Eicosanoid profiling in EBC points to alterations in asthma, especially in its phenotype characterized by aspirin hypersensitivity. The method seems suitable for monitoring the disease.

\section{REFERENCES}

1. Kharitonov SA, Barnes PJ. Exhaled markers of inflammation. Curr Opin Allergy Clin Immunol 2001;1:217-24.

2. Fens N, Zwinderman AH, van der Schee MP, de Nijs SB, Dijkers E, Roldaan AC, et al. Exhaled breath profiling enables discrimination of chronic obstructive pulmonary disease and asthma. Am J Respir Crit Care Med 2009;180:1076-82.

3. Dallinga JW, Robroeks CM, van Berkel JJ, Moonen EJ, Godschalk RW, Jobsis Q, et al. Volatile organic compounds in exhaled breath as a diagnostic tool for asthma in children. Clin Exp Allergy 2010;40:68-76.

4. Horvath I, Hunt J, Barnes PJ, Alving K, Antczak A, Baraldi E, et al. Exhaled breath condensate: methodological recommendations and unresolved questions. Eur Respir J 2005;26:523-48.

5. Szczeklik A, Sanak M. The broken balance in aspirin hypersensitivity. Eur J Pharmacol 2006;533:145-55.

6. Stevenson DD, Szczeklik A. Clinical and pathologic perspectives on aspirin sensitivity and asthma. J Allergy Clin Immunol 2006;118:773-88.
7. Smith CM, Christie PE, Hawksworth RJ, Thien F, Lee TH. Urinary leukotriene E4 levels after allergen and exercise challenge in bronchial asthma. Am Rev Respir Dis 1991;144:1411-3.

8. Sanak M, Gielicz A, Nagraba K, Kaszuba M, Kumik J, Szczeklik A. Targeted eicosanoids lipidomics of exhaled breath condensate in healthy subjects. J Chromatogr B Analyt Technol Biomed Life Sci 2010;878:1796-800.

9. Szczeklik A, Nizankowska E, Duplaga M. Natural history of aspirin-induced asthma. AIANE Investigators. European Network on Aspirin-Induced Asthma. Eur Respir J 2000;16:432-6.

10. Expert Panel report 3 (epr-3): guidelines for the diagnosis and management of asthma-summary report 2007. J Allergy Clin Immunol 2007;120(suppl): S94-138.

11. Nathan RA, Sorkness CA, Kosinski M, Schatz M, Li JT, Marcus P, et al. Development of the asthma control test: a survey for assessing asthma control. J Allergy Clin Immunol 2004;113:59-65.

12. Tsikas D, Schwedhelm E, Gutzki FM, Frolich JC. Gas chromatographic mass spectrometric discrimination between 8-iso-prostaglandin E-2 and prostaglandin E-2 through derivatization by O-(2,3,4,5,6-pentafluorobenzyl)hydroxyl amine. Anal Biochem 1998;261:230-2.

13. Murphy RC, Barkley RM, Zemski Berry K, Hankin J, Harrison K, Johnson C, et al. Electrospray ionization and tandem mass spectrometry of eicosanoids. Anal Biochem 2005;346:1-42.

14. Tsikas D. Application of gas chromatography-mass spectrometry and gas chromatography-tandem mass spectrometry to assess in vivo synthesis of prostaglandins, thromboxane, leukotrienes, isoprostanes and related compounds in humans. J Chromatogr B Biomed Sci Appl 1998;717:201-45.

15. Bochenek G, Nagraba K, Nizankowska E, Szczeklik A. A controlled study of 9alpha,11beta-PGF2 (a prostaglandin D2 metabolite) in plasma and urine of patients with bronchial asthma and healthy controls after aspirin challenge. J Allergy Clin Immunol 2003;111:743-9.

16. Szczeklik A, Sladek K, Dworski R, Nizankowska E, Soja J, Sheller J, et al. Bronchial aspirin challenge causes specific eicosanoid response in aspirin-sensitive asthmatics. Am J Respir Crit Care Med 1996;154:1608-14.

17. Ferreri NR, Howland WC, Stevenson DD, Spiegelberg HL. Release of leukotrienes, prostaglandins, and histamine into nasal secretions of aspirin-sensitive asthmatics during reaction to aspirin. Am Rev Respir Dis 1988;137:847-54.

18. Kowalski ML. Aspirin-sensitive rhinosinusitis and asthma. Clin Allergy Immunol 2007;19:147-75

19. Gaber F, Daham K, Higashi A, Higashi N, Gulich A, Delin I, et al. Increased levels of cysteinyl-leukotrienes in saliva, induced sputum, urine and blood from patients with aspirin-intolerant asthma. Thorax 2008;63:1076-82.

20. Higashi N, Taniguchi M, Mita H, Osame M, Akiyama K. A comparative study of eicosanoid concentrations in sputum and urine in patients with aspirin-intolerant asthma. Clin Exp Allergy 2002;32:1484-90.

21. Christie PE, Tagari P, Ford-Hutchinson AW, Charlesson S, Chee P, Arm JP, et al. Urinary leukotriene E4 concentrations increase after aspirin challenge in aspirinsensitive asthmatic subjects. Am Rev Respir Dis 1991;143:1025-9.

22. Mastalerz L, Sanak M, Gawlewicz-Mroczka A, Gielicz A, Cmiel A, Szczeklik A. Prostaglandin E2 systemic production in patients with asthma with and without aspirin hypersensitivity. Thorax 2008;63:27-34.

23. Antczak A, Montuschi P, Kharitonov S, Gorski P, Barnes PJ. Increased exhaled cysteinyl-leukotrienes and 8-isoprostane in aspirin-induced asthma. Am J Respir Crit Care Med 2002;166:301-6.

24. Sanak M, Kielbasa B, Bochenek G, Szczeklik A. Exhaled eicosanoids following oral aspirin challenge in asthmatic patients. Clin Exp Allergy 2004;34: 1899-904.

25. Dressel H, Muller F, Fischer R, Rommelt H, Hohlfeld JM, Behr J, et al. Independent information of nonspecific biomarkers in exhaled breath condensate. Respiration 2010;80:401-9.

26. McCafferty JB, Bradshaw TA, Tate S, Greening AP, Innes JA. Effects of breathing pattern and inspired air conditions on breath condensate volume, $\mathrm{pH}$, nitrite, and protein concentrations. Thorax 2004;59:694-8.

27. Schwarz K, Biller H, Windt H, Koch W, Hohlfeld JM. Characterization of exhaled particles from the healthy human lung-a systematic analysis in relation to pulmonary function variables. J Aerosol Med Pulm Drug Deliv 2010;23: 371-9.

28. Bianco S, Robuschi M, Ceserani R, Gandolfi C. Effects of prostacyclin on aspecifically and specifically induced bronchoconstriction in asthmatic patients. Eur J Respir Dis Suppl 1980;106:81-7.

29. Szczeklik A, Gryglewski RJ, Nizankowska E, Nizankowski R, Musial J. Pulmonary and anti-platelet effects of intravenous and inhaled prostacyclin in man. Prostaglandins 1978;16:651-60.

30. Nizankowska E, Czerniawska-Mysik G, Szczeklik A. Lack of effect of i.v. prostacyclin on aspirin-induced asthma. Eur J Respir Dis 1986;69:363-8. 
31. Debley JS, Ohanian AS, Spiekerman CF, Aitken ML, Hallstrand TS. Effects of bronchoconstriction, minute ventilation, and deep inspiration on the composition of exhaled breath condensate (EBC). Chest 2011;139:16-22.

32. Moreno JJ. New aspects of the role of hydroxyeicosatetraenoic acids in cell growth and cancer development. Biochem Pharmacol 2009;77:1-10.

33. Kim DC, Hsu FI, Barrett NA, Friend DS, Grenningloh R, Ho IC, et al. Cysteinyl leukotrienes regulate Th2 cell-dependent pulmonary inflammation. J Immunol 2006; 176:4440-8

34. Claesson HE. On the biosynthesis and biological role of eoxins and 15-lipoxygenase-1 in airway inflammation and Hodgkin lymphoma. Prostaglandins Other Lipid Mediat 2009;89:120-5.

35. Brash AR, Boeglin WE, Chang MS. Discovery of a second 15S-lipoxygenase in humans. Proc Natl Acad Sci U S A 1997;94:6148-52.

36. Sebaldt RJ, Sheller JR, Oates JA, Roberts LJ II, FitzGerald GS. Inhibition of eicosanoid biosynthesis by glucocorticoids in humans. Proc Natl Acad Sci U S A 1990; 87:6974-8.
37. Sachs-Olsen C, Sanak M, Lang AM, Gielicz A, Mowinckel P, Lodrup Carlsen KC, et al. Eoxins: A new inflammatory pathway in childhood asthma. J Allergy Clin Immunol 2010;126:859-67, e9.

38. Szczeklik A, Niżankowska-Mogilnicka E, Sanak M. Hypersensitivity to aspirin and nonsteroidal anti-inflammatory drugs. In: Adkinson NF, Busse WW, Bochner BS, Holgate ST, Simons FER, Lemanske RF Jr, editors. Middleton's allergy: principles and practice. 7th ed Mosby Elsevier; 2009 p. 1227-43.

39. Jinnai N, Sakagami T, Sekigawa T, Kakihara M, Nakajima T, Yoshida K, et al. Polymorphisms in the prostaglandin E2 receptor subtype 2 gene confer susceptibility to aspirinintolerant asthma: a candidate gene approach. Hum Mol Genet 2004;13:3203-17.

40. Sanak M, Bochenek G, Faber J, Plutecka H, Szczeklik A. Elevated urinary leukotriene E4 excretion in asthma: a comparison of HPLC-mass spectrometry and ELISA. Allergy 2010;65:663-4.

41. Lu R, Kanai N, Bao Y, Schuster VL. Cloning, in vitro expression, and tissue distribution of a human prostaglandin transporter cDNA(hPGT). J Clin Invest 1996; 98:1142-9.

Don't miss a single issue of the journal! To ensure prompt service when you change your address, please photocopy and complete the form below.

Please send your change of address notification at least six weeks before your move to ensure continued service. We regret we cannot guarantee replacement of issues missed due to late notification.

JOURNAL TITLE:

Fill in the title of the journal here.

\section{OLD ADDRESS:}

Affix the address label from a recent issue of the journal here.

\section{NEW ADDRESS:}

Clearly print your new address here.

Name

Address

City/State/ZIP
COPY AND MAIL THIS FORM TO:

Elsevier Periodicals Customer Service 3251 Riverport Lane

Maryland Heights, MO 63043
OR FAX TO:

314-447-8029
OR PHONE:

800-654-2452

Outside the U.S.:

314-447-8871
OR E-MAIL:

Journals Customer Serviceusa@elsevier.com 
TABLE E1. Eicosanoid concentration in EBC: unadjusted concentration

\begin{tabular}{|c|c|c|c|c|}
\hline & $\begin{array}{l}\text { Asthmatic subjects } \\
\qquad(\mathrm{n}=115)\end{array}$ & $\begin{array}{l}\text { Subjects with } \\
\text { aspirin-intolerant } \\
\text { asthma }(n=62)\end{array}$ & $\begin{array}{l}\text { Subjects with ATA } \\
(\mathrm{n}=54)\end{array}$ & $\begin{array}{l}\text { Healthy control } \\
\text { subjects }(n=38)\end{array}$ \\
\hline 5-HETE & $2.82(1.88-5.41)$ & $3.90(2.25-5.80) \|$ & $2.26(1.43-3.32)$ & $2.75(1.80-4.89)$ \\
\hline 12-HETE & $3.50(2.52-6.42)$ & $3.63(2.76-6.70)$ & $3.36(2.22-6.14)$ & $3.50(2.39-4.51)$ \\
\hline 15-HETE & $4.81(3.16-7.02)$ & $6.37(3.74-9.30) \|$ & $3.67(2.30-5.74)$ & $2.60(2.15-3.93) \ddagger$ \\
\hline $\mathrm{PGE}_{2}$ & $0.64(0.39-1.07)$ & $0.55(0.33-0.98)$ & $0.66(0.49-1.12)$ & $0.78(0.39-1.56)$ \\
\hline PGEM & $99.2(48.7-191)$ & $169(91-300) \Phi$ & $55.0(27.6-103)$ & $108(24.6-184)$ \\
\hline $\mathrm{PGD}_{2}$ & $0.79(0.50-1.26)$ & $0.91(0.66-1.25)$ & $0.68(0.46-1.27)$ & $0.70(0.43-1.68)$ \\
\hline $9 \alpha, 11 \beta \mathrm{PGF}_{2}$ & $0.49(0.20-0.89)$ & $0.73(0.47-1.18)$ & $0.22(0.12-0.48)$ & $0.38(0.22-0.63)$ \\
\hline $\mathrm{LTB}_{4}$ & $5.10(2.83-7.63)$ & $5.83(3.41-8.87) \|$ & $3.68(2.58-6.09)$ & $8.07(4.65-16.41) \ddagger$ \\
\hline $\mathrm{LTC}_{4}$ & $1.98(1.21-3.06)$ & $1.95(1.09-2.68)$ & $1.98(1.31-3.24)$ & $1.63(0.75-3.10)$ \\
\hline $\mathrm{LTD}_{4}$ & $1.03(0.59-2.18)$ & $0.72(0.48-1.76)$ & $1.18(0.77-2.66)$ & $1.14(0.49-2.09)$ \\
\hline $\mathrm{LTE}_{4}$ & $1.37(0.77-1.91)$ & 1.09 (0.64-1.69) & $1.71(1.22-2.29)$ & $1.16(0.75-2.00)$ \\
\hline Eoxin $C_{4}$ & $0.43(0.30-0.93)$ & $0.37(0.26-0.86)$ & $0.51(0.33-0.95)$ & $0.69(0.37-0.94)$ \\
\hline Eoxin $\mathrm{D}_{4}$ & $0.57(0.37-0.93)$ & $0.47(0.34-0.61) \|$ & $0.67(0.43-1.03)$ & $0.87(0.57-1.62)^{*}$ \\
\hline Eoxin $\mathrm{E}_{4}$ & $1.80(0.99-4.23)$ & $2.07(1.02-4.64)$ & $1.70(0.98-4.19)$ & $3.70(2.18-8.72)^{*}$ \\
\hline 11-Dehydro- $\mathrm{TXB}_{2}$ & $5.16(4.10-6.45)$ & $4.77(4.03-5.93) \|$ & $6.25(4.40-6.83)$ & $5.37(4.19-6.67)$ \\
\hline 6-Keto-PGF ${ }_{1 \alpha}$ & $14.08(10.47-17.16)$ & $15.84(13.21-17.50)$ ฯ & $11.90(7.64-14.54)$ & $7.93(6.92-14.15)$ \\
\hline $\mathrm{PGF}_{2 \alpha}$ & $0.73(0.37-1.16)$ & $0.75(0.40-1.07)$ & $0.69(0.28-1.28)$ & $0.41(0.23-0.80) \dagger$ \\
\hline 8-Iso-PGF $2 \alpha$ & $0.32(0.20-0.47)$ & $0.35(0.25-0.49) \|$ & $0.29(0.18-0.37)$ & $0.26(0.15-0.9)$ \\
\hline Lipoxin $\mathrm{A}_{4}$ & $0.29(0.18-0.45)$ & $0.26(0.19-0.41)$ & $0.31(0.17-0.55)$ & $0.36(0.22-1.02)^{*}$ \\
\hline $\mathrm{PA}$ & $391(308-495)$ & $404(323-666) \S$ & $372(300-472)$ & $617(431-731) \$$ \\
\hline
\end{tabular}

Eicosanoids are shown in picograms per milliliter, and palmitic acid is shown in nanograms per milliliter. Values are presented as medians (25th-75th percentile).

$P A$, Palmitic acid.

$* P<.05, \dagger P<.01$, or $\ddagger P<.001$ for the contrast between asthmatic and healthy control subjects.

$\S P<.05, \| P<0.01$, or $\llbracket P<.001$ for the contrast between subjects with aspirin-intolerant asthma and subjects with ATA. 
TABLE E2. Canonical discrimination functions standardized by within-group variances for the full model and a stepwise selection

\begin{tabular}{|c|c|c|c|c|}
\hline \multicolumn{3}{|c|}{ Full model } & \multicolumn{2}{|c|}{ Stepwise model } \\
\hline Eicosanoid & Factor (1) & Factor (2) & Factor (1) & Factor (2) \\
\hline 5-HETE & 0.168 & 0.238 & & \\
\hline 12-HETE & 0.260 & -0.564 & & \\
\hline 15-HETE & 0.003 & 0.248 & 0.108 & 0.311 \\
\hline $\mathrm{PGE}_{2}$ & -0.452 & -0.867 & -0.411 & 0.508 \\
\hline PGEM & 0.710 & 0.301 & & \\
\hline $\mathrm{PGD}_{2}$ & 0.442 & 0.425 & 0.650 & 0.024 \\
\hline $9 \alpha, 11 \beta \mathrm{PGF}_{2}$ & 1.034 & -0.568 & 0.652 & 0.783 \\
\hline $\mathrm{LTB}_{4}$ & 0.103 & -0.272 & & \\
\hline $\mathrm{LTC}_{4}$ & 0.089 & 0.084 & -0.822 & 0.301 \\
\hline $\mathrm{LTD}_{4}$ & -0.107 & 0.329 & & \\
\hline $\mathrm{LTE}_{4}$ & -0.601 & 0.396 & -0.182 & -0.239 \\
\hline Eoxin $\mathrm{C}_{4}$ & -0.206 & 0.192 & & \\
\hline Eoxin $\mathrm{D}_{4}$ & -0.141 & -0.114 & 0.188 & 0.236 \\
\hline Eoxin $E_{4}$ & -0.260 & -0.441 & & \\
\hline 11-Dehydro-TXB & -0.558 & 0.041 & -0.298 & 0.601 \\
\hline 6-Keto-PGF ${ }_{1 \alpha}$ & 0.179 & 0.464 & 0.596 & 0.314 \\
\hline $\mathrm{PGF}_{2 \alpha}$ & -0.745 & 0.562 & 0.373 & -0.422 \\
\hline 8-Iso-PGF ${ }_{2 \alpha}$ & -0.277 & 0.183 & -0.950 & -0.723 \\
\hline Lipoxin $\mathrm{A}_{4}$ & 0.050 & -0.115 & 0.411 & -0.976 \\
\hline
\end{tabular}

